\title{
Food allergy is associated with recurrent respiratory tract infections during childhood
}

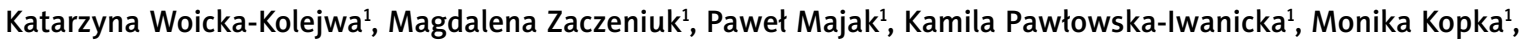 \\ Wlodzimierz Stelmach², Joanna Jerzyńska ${ }^{1}$, Iwona Stelmach ${ }^{1}$
}

${ }^{1}$ Department of Pediatrics and Allergy, Medical University of Lodz, Lodz, Poland

${ }^{2}$ Department of Social and Preventive Medicine, Medical University of Lodz, Lodz, Poland

Adv Dermatol Allergol 2016; XXXIII (2): 109-113

DOI: 10.5114/ada.2016.59151

\begin{abstract}
Introduction: To find out whether children with food allergy have an increased risk of recurrent upper and lower respiratory tract infections and of asthma.

Aim: To describe the clinical profile of children diagnosed with food allergy referred to the Allergy Clinic.

Material and methods: We conducted a retrospective study to assess the patients' demographic, anthropometric and clinical data. The analysis included data of all children by the age of 10 years (registered with the Allergy Clinic between 2012 and 2013) in whom IgE mediated food allergy had been diagnosed during 18 months of observation. Results: We included 280 children into the analysis. Recurrent respiratory tract infections (rRTI), asthma and gastrointestinal (GI) symptoms were observed in 153 (54.6\%), 96 (34.3\%), 39 (13.9\%), respectively, with a significant increasing trend across age-subgroups. In children from 1 to 2 years old, sensitization to $\beta$-lactoglobulin increased the risk of $\mathrm{rRTI}(\mathrm{OR}=3.91 ; 95 \% \mathrm{Cl}: 1.03-14.87)$. In older children sensitization to allergens other than milk or egg decreases the risk of $r R T I(O R=0.25 ; 95 \% \mathrm{Cl}$ : 0.10-0.62); sensitization to egg decreased the risk of asthma diagnosis $(\mathrm{OR}=0.09 ; 95 \% \mathrm{Cl}: 0.01-0.75)$. We did not identify food allergens which change the risk of $\mathrm{Gl}$ symptoms in children. This finding was consistent throughout all age-subgroups.

Conclusions: Sensitization to $\beta$-lactoglobulin increased the risk of rRTI in children under 2 years of age nearly four times. The presence of sensitization to food allergens above 3 years of age did not increase the risk of developing clinical presentation of food allergy other than atopic dermatitis.
\end{abstract}

Key words: food allergy, recurrent respiratory infections, children.

\section{Introduction}

Food allergy is usually mediated by IgE antibody to specific food proteins and determination of specific lgE antibody is the basis of the common diagnostic test for food allergy. There is still a controversy over the role of specific food allergens in the mechanism that evokes the atopic dermatitis. The main food allergens in childhood are cow's milk proteins and eggs.

Epidemiological data indicate that the incidence of food allergy in children is increasing [1, 2]. This has become a common diagnostic and management challenge for pediatricians worldwide. Recent reports suggest that for both egg and milk allergy retreat is not occurring as quickly as previously thought, with allergy persisting into adolescence [3]. It is not clear if the natural history of food allergy is changing. First symptoms in infants and young children affect the skin and gastrointestinal tract (it is the main cause of hospitalizations and medical appointments in this age group). For older children, the main manifestation is asthma symptoms (wheezing, cough) [3]. The role of food allergy, especially cow's milk and egg's allergy as a risk factor for asthma and infections has been controversial. We conducted a retrospective study to find out whether children with food allergy have an increased risk of recurrent upper and lower respiratory tract infections and of asthma.

\section{Aim}

Demographic and anthropometric characteristic were analyzed because all factors seem to be involved in the development of atopic disorders.

Address for correspondence: Iwona Stelmach MD, PhD, Prof., Department of Pediatrics and Allergy, N. Copernicus Hospital, 62 Pabianicka St, 93-513 Lodz, Poland, phone: +48 4268959 72, fax: +48 4268959 73, e-mail: iwona.stelmach@kopernik.lodz.pl Received: 25.09.2014, accepted: 19.01.2015. 


\section{Material and methods}

The analysis included data of all children by the age of 10 years (registered with the Allergy Clinic of Nicolaus Copernicus Hospital in Lodz between 2012 and 2013) in whom IgE mediated food allergy had been diagnosed during 18 months of observation. All the children were followed in the same hospital before coming to the allergy clinic.

Allergen-specific IgE (slgE) concentrations in the serum were determined for the following allergens: $\beta$-lactoglobulin, casein, egg yolk and egg white, carrot, apple, orange, tomato, peanut, wheat, soya, celery, cod, pork and chicken meat. Specific lgE > $0.35 \mathrm{KU} / \mathrm{l}$ and a clear history of a reaction confirmed a diagnosis of IgEmediated food allergy.

Data were retrieved from standardized medical files. The analysis included following data:

a) perinatal period data (way of childbirth, prematurity, birth weight);

b) atopic family history;

c) asthma in family;

d) clinical data:

- skin manifestations (atopic dermatitis, urticaria, angioedema, erythema),

- gastrointestinal symptoms (vomiting, spitting, prolonged baby colic, changes in stool, constipation, diarrhea, aphthous inflammation of oral cavity, eosinophilic gastroenteropathies, gastroesophageal reflux disease (GERD), dietary protein enterocolitis and proctitis),

- recurrent upper or lower respiratory infections (doctor-diagnosed) - were defined as ones occurring more than six times a year,

- asthma - in accordance with the international guidelines, the diagnosis of asthma in children above 5 years of age was confirmed by the results of pul- monary function testing and/or by the response to anti-asthmatic treatment; in children below the age of 5 years, asthma was diagnosed according to the Api index.

The study was approved by the Medical University of Lodz Ethics Committee.

\section{Statistical analysis}

All comparisons were assessed by logistic regression. First, logistic regression was used to assess the relationship between dependent variables and each of the independent variables. A stepwise procedure was then used to select variables. Multivariate models allowed to assess the interaction effect of potential confounders. All of the statistical analyses were performed using SPSS 11.5. The null hypothesis was rejected if $p<0.05$.

\section{Results}

We included 280 children into the analysis (all children diagnosed with food allergy who were referred to our Allergy Center during 18 months of observation). Recurrent respiratory tract infections (rRTI) and asthma diagnosis were observed in 153 (54.6\%) and 96 (34.3\%) patients, respectively, with a significant increasing trend across age-subgroups (Table 1). Gastrointestinal (Gl) symptoms were observed in 39 (13.9\%) of all children. Clinical characteristics of the study population are given in Table 1.

We did not observe any significant associations between birth weight, Apgar score, gender, total IgE, time/ method of delivery and any dependent variable such as rRTI, asthma diagnosis and GI symptoms.

In the next step we introduced logistic regression analysis to point out the food allergy profile as risk fac-

Table 1. Patient characteristics

\begin{tabular}{|c|c|c|c|c|}
\hline Parameter & $\begin{array}{c}\text { Age }<1 \text { year } \\
N=41\end{array}$ & $\begin{array}{c}\text { Age } 1-2 \text { years } \\
\quad N=42\end{array}$ & $\begin{array}{c}\text { Age } 2-3 \text { years } \\
N=35\end{array}$ & $\begin{array}{c}\text { Age }>3 \text { years } \\
\quad N=162\end{array}$ \\
\hline Male & $26(63.4)$ & $31(73.8)$ & $24(68.6)$ & $87(53.7)$ \\
\hline Female & $15(36.6)$ & $11(26.2)$ & $11(31.4)$ & $75(46.3)$ \\
\hline APGAR [points] & $10(9-10)$ & $9(9-10)$ & $10(9-10)$ & $10(9-10)$ \\
\hline Birth weight $[\mathrm{g}]$ & $3340(3100-3690)$ & $3500(3000-3750)$ & $3450(3050-3680)$ & $3350(3100-3650)$ \\
\hline Total IgE [IU/I] & $37(8-100)$ & $78(25-164)$ & $108(39-352)$ & $151(66-418)$ \\
\hline Prematurity & $1(2.4)$ & $2(4.8)$ & $0(0.0)$ & $10(6.2)$ \\
\hline Caesarian section & $17(47.2)$ & $19(51.4)$ & $13(39.4)$ & $49(32.0)$ \\
\hline Gastro-intestinal symptoms & $7(17.1)$ & $11(26.2)$ & $4(11.4)$ & $17(10.5)$ \\
\hline Recurrent infections & $14(34.1)$ & $21(50.0)$ & $19(54.3)$ & 99 (61.1) \\
\hline Asthma & $0(0.0)$ & $9(21.4)$ & $11(31.4)$ & $76(46.9)$ \\
\hline Asthma in family & $19(47.5)$ & $22(52.4)$ & $13(37.1)$ & $71(43.8)$ \\
\hline
\end{tabular}




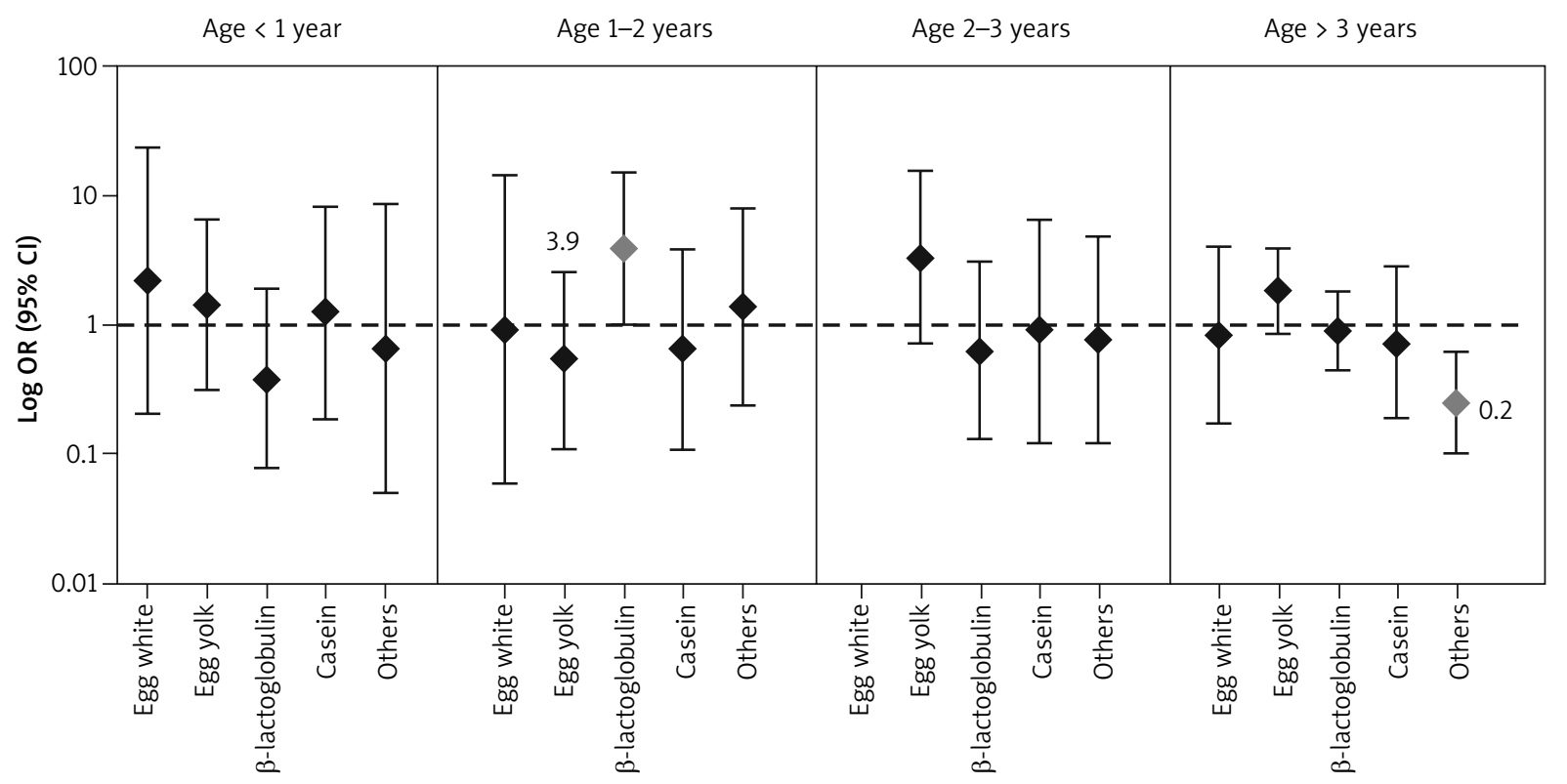

Figure 1. Sensitization to food allergens as a risk of recurrent respiratory tract infections

Table 2. Sensitization to food allergens as a risk of gastrointestinal symptoms. Data are presented as odds ratios (OR) with $95 \% \mathrm{Cl}$ in sub-groups according to the age of patients

\begin{tabular}{|c|c|c|c|c|}
\hline Coefficient & $\mathrm{OR}^{\mathrm{a}}$ & \multicolumn{2}{|c|}{$95 \% \mathrm{Cl}$} & $P$-value \\
\hline \multicolumn{5}{|l|}{ Age < 1 year: } \\
\hline Egg white & 1.83 & 0.12 & 26.96 & 0.6582 \\
\hline Egg yolk & 0.62 & 0.09 & 4.30 & 0.6266 \\
\hline$\beta$-lactoglobulin & 2.91 & 0.43 & 19.42 & 0.2712 \\
\hline Casein & 0.16 & 0.01 & 3.42 & 0.2438 \\
\hline Others & 3.91 & 0.17 & 88.24 & 0.3916 \\
\hline \multicolumn{5}{|l|}{ Age $1-2$ years: } \\
\hline Egg white & 2.79 & 0.18 & 43.27 & 0.4636 \\
\hline Egg yolk & 0.63 & 0.13 & 3.13 & 0.5689 \\
\hline$\beta$-lactoglobulin & 1.82 & 0.37 & 8.94 & 0.4591 \\
\hline Casein & 0.29 & 0.03 & 3.04 & 0.3010 \\
\hline Others & 0.41 & 0.04 & 4.20 & 0.4543 \\
\hline \multicolumn{5}{|l|}{ Age 2-3 years: } \\
\hline Egg white & - & - & - & - \\
\hline Egg yolk & 0.18 & 0.01 & 2.98 & 0.2323 \\
\hline$\beta$-lactoglobulin & 1.45 & 0.07 & 29.89 & 0.8099 \\
\hline Casein & 11.02 & 0.53 & 230.35 & 0.1219 \\
\hline Others & - & - & - & - \\
\hline \multicolumn{5}{|l|}{ Age $>3$ years: } \\
\hline Egg white & 0.40 & 0.05 & 2.96 & 0.3667 \\
\hline Egg yolk & 0.40 & 0.13 & 1.26 & 0.1165 \\
\hline$\beta$-lactoglobulin & 0.57 & 0.20 & 1.64 & 0.2947 \\
\hline Casein & 1.41 & 0.15 & 13.65 & 0.7675 \\
\hline Others & 0.33 & 0.05 & 2.12 & 0.2442 \\
\hline
\end{tabular}

Table 3. Sensitization to food allergens as a risk of recurrent respiratory tract infections. Data are presented as OR (odds ratios) with $95 \% \mathrm{Cl}$ in sub-groups according to the age of patients

\begin{tabular}{lllll}
\hline Coefficient & OR $^{\mathrm{a}}$ & \multicolumn{2}{c}{$95 \% \mathrm{Cl}$} & $P$-value \\
\hline Age $<1$ year: & & & & \\
\hline Egg white & 2.24 & 0.21 & 23.98 & 0.5057 \\
\hline Egg yolk & 1.43 & 0.31 & 6.65 & 0.6470 \\
\hline$\beta$-lactoglobulin & 0.38 & 0.08 & 1.90 & 0.2377 \\
\hline Casein & 1.26 & 0.19 & 8.15 & 0.8115 \\
\hline Others & 0.66 & 0.05 & 8.57 & 0.7508 \\
\hline Age 1-2 years: & & & & \\
\hline Egg white & 0.92 & 0.06 & 14.69 & 0.9536 \\
\hline Egg yolk & 0.55 & 0.11 & 2.63 & 0.4516 \\
\hline$\beta$-lactoglobulin & 3.91 & 1.03 & 14.87 & 0.0454 \\
\hline Casein & 0.66 & 0.11 & 3.88 & 0.6471 \\
\hline Others & 1.40 & 0.24 & 8.06 & 0.7089 \\
\hline
\end{tabular}

Age $2-3$ years:

\begin{tabular}{lcccc}
\hline Egg white & - & - & - & - \\
\hline Egg yolk & 3.36 & 0.73 & 15.44 & 0.1188 \\
\hline$\beta$-lactoglobulin & 0.63 & 0.13 & 3.09 & 0.5712 \\
\hline Casein & 0.90 & 0.12 & 6.51 & 0.9153 \\
\hline Others & 0.78 & 0.12 & 4.89 & 0.7897 \\
\hline
\end{tabular}

Age > 3 years:

\begin{tabular}{lllll}
\hline Egg white & 0.83 & 0.17 & 4.07 & 0.8220 \\
\hline Egg yolk & 1.84 & 0.87 & 3.89 & 0.1111 \\
\hline$\beta$-lactoglobulin & 0.89 & 0.44 & 1.80 & 0.7441 \\
\hline Casein & 0.74 & 0.19 & 2.88 & 0.6640 \\
\hline Others & 0.25 & 0.10 & 0.62 & 0.0028
\end{tabular}

${ }^{a}$ Dependent variable: gastrointestinal symptoms. - OR could not be estimated. 
tors for symptoms other than AD in children with sensitization to food allergens (Figure 1).

We did not identify food allergens which change the risk of Gl symptoms in children with sensitization to food allergens (Table 2). This finding was consistent throughout all age-subgroups. We found that in children from 1 to 2 years old sensitization to $\beta$-lactoglobulin increases the risk of $\mathrm{rRTI}(\mathrm{OR}=3.91 ; 95 \% \mathrm{Cl}: 1.03-14.87)$ (Table 3). In older children sensitization to allergens other than milk or egg decreases the risk of $\mathrm{rRTI}(\mathrm{OR}=0.25 ; 95 \% \mathrm{Cl}$ : 0.10 0.62) (Table 3). Finally, we also observed that in older children sensitization to eggs decreases the risk of asthma diagnosis ( $\mathrm{OR}=0.09 ; 95 \% \mathrm{Cl}$ : 0.01-0.75) (Table 4).

\section{Discussion}

Our study revealed that sensitization to $\beta$-lactoglobulin, whey protein (not a casein or other food allergens) increase the risk of recurrent respiratory tract infections in children under 2 years of age nearly four times. In opposite to several studies, we had not confirmed any connection between food allergy and asthma in our study group [4]. Another result of our study is that the presence of sensitization to food allergens above 3 years of age, does not increase the risk of developing clinical presentation of food allergy other than atopic dermatitis, which confirms the modification to the Api index made by Guilbert [5].

Table 4. Sensitization to food allergens as a risk of asthma. Data are presented as OR (odds ratios) with $95 \% \mathrm{Cl}$ in subgroups according to the age of patients

\begin{tabular}{lcccc}
\hline Coefficient & OR $^{\mathrm{a}}$ & \multicolumn{2}{c}{$95 \% \mathrm{Cl}$} & $P$-value \\
\hline Age 1-2 years: & & & & \\
\hline Egg white & 0.55 & 0.02 & 12.99 & 0.7094 \\
\hline Egg yolk & 2.99 & 0.28 & 32.34 & 0.3666 \\
\hline$\beta$-lactoglobulin & 6.28 & 0.62 & 63.32 & 0.1193 \\
\hline Casein & 1.49 & 0.23 & 9.58 & 0.6720 \\
\hline Others & 0.95 & 0.12 & 7.44 & 0.9599 \\
\hline Age 2-3 years: & & & & \\
\hline Egg white & - & - & - & - \\
\hline Egg yolk & 1.04 & 0.21 & 5.25 & 0.9603 \\
\hline$\beta$-lactoglobulin & 1.16 & 0.22 & 6.16 & 0.8613 \\
\hline Casein & 0.81 & 0.10 & 6.83 & 0.8472 \\
\hline Others & 3.93 & 0.63 & 24.54 & 0.1436 \\
\hline Age $>$ 3 years: & & & & \\
\hline Egg white & 0.09 & 0.01 & 0.75 & 0.0257 \\
\hline Egg yolk & 0.82 & 0.41 & 1.66 & 0.5822 \\
\hline$\beta$-lactoglobulin & 0.92 & 0.47 & 1.80 & 0.8077 \\
\hline Casein & 0.44 & 0.10 & 1.84 & 0.2612 \\
\hline Others & 1.39 & 0.56 & 3.46 & 0.4739 \\
\hline
\end{tabular}

a Dependent variable: gastrointestinal symptoms. - OR could not be estimated.
Upper and lower respiratory infections are one of the leading causes of morbidity among children. Overuse of antibiotics is nowadays a global problem especially in pediatric care. We know that rational antibiotics' use should be propagated because of adverse effects and resistance to drugs that is still growing [6]. It was found that children with cow's milk allergy in infancy (even when food allergy is properly treated) are more exposed to recurrent otitis media during childhood $[7,8]$. In medical literature, there are also some reports about the correlation between cow's milk (but not wheat allergy) and chronic nasal polyp occurrence [9]. The study conducted in Italian preschool children also revealed that there is a significant relationship between atopy and recurrent respiratory infections [10]. The signs and symptoms of respiratory infections are often difficult to differentiate from the signs and symptoms of allergy. Many researches revealed that use of hydrolyzed formulas when breast feeding is not possible or there is a need to supplement breast feeding, reduces the risk of atopic dermatitis in children with an atopic family history [11-13]. There are various positions on the subject and their analysis [14, 15]. Another subject that should be discussed is the fact that cow's milk allergy has significant implications on the quality of life of both parents and the affected child and very high costs to the society. A health economic evaluation published in 2011 on the outcome for children up to 6 years of age showed that both extensively hydrolyzed casein formulas (eHF-C) and extensively hydrolyzed whey formulas (eHF-W) are cost-effective for allergy prevention [16]. In comparison to eHF-C, eHF-W has the advantage of being more palatable and less expensive. Unfortunately, none of the studies discussed the use of hydrolyzed formulae in such important group of patients, namely those with Ig-E mediated food allergy and recurrent respiratory infections.

\section{Conclusions}

Taking into account our results we assume that in children with diagnosed cow's milk allergy (CMA) and recurrent respiratory infections, eHF-W can be considered up to the second year of life, even if the symptoms of atopic disorders decreased. Although the spontaneous resolution of CMA is common, it is not always complete $[14,15]$. The increasing percentage of children with recurrent respiratory infections and food allergy worldwide, should be a brain teaser for all researchers. This leads us to a conclusion that preventive activities seem to be the most effective form to combat the food allergy epidemic and all possible consequences it brings about. The results of our study point to some new issues in the treatment of cow's milk allergy. However, our study was carried on a small group of children, that is why it may not be objective. There is a need for further prospective, cohort studies to confirm our findings. Also, the clinical benefit of an 
elimination diet in children with CMA and the recurrence of respiratory infections should be evaluated until general recommendations can be given. We are still searching for the answer: whether the food allergy really increases the risk of respiratory infections and how it affects the life of our young patients in their future.

\section{Acknowledgments}

This study was funded by grant 503-2056-1 from the Medical University of Lodz, Poland.

\section{Conflict of interest}

The authors declare no conflict of interest.

\section{References}

1. Noh G, Ahn HS, Cho NY, et al. The clinical significance of food specific IgE/lgG4 in food specific atopic dermatitis. Pediatr Allergy Immunol 2007; 18: 63-70.

2. Lowe A, Hosking CS, Bennett CM, et al. Effect of a partially hydrolyzed whey infant formula at weaning on risk of allergic disease in high-risk children: a randomized controlled trial. J Allergy Clin Immunol 2011; 128: 360-5.

3. Peters RL, Gurrin LC, Dharmage SC, et al. The natural history of IgE-mediated food allergy: can skin prick tests and serum-specific IgE predict the resolution of food allergy? Int J Environ Res Public Health 2013; 10: 5039-61.

4. Tomac N, Turan E, Ertan U, Ozmen S. Cow's milk allergy as a risk factor for forthcoming wheezing attacks. Allergy 2004; 59: 1017-8.

5. Guilbert TW, Morgan WJ, Zeiger RS, et al. Atopic characteristics of children with recurrent wheezing at high risk for the development of childhood asthma. J Allergy Clin Immunol 2004; 114: 1282-7.

6. Dupont C, Chouraqui JP, de Boissieu D, et al. Dietary treatment of cows' milk protein allergy in childhood: a commentary by the Committee on Nutrition of the French Society of Paediatrics. Br J Nutr 2012; 107: 325-38.

7. Lubianca Neto JF, Hemb L, Silva DB. Systematic literature review of modifiable risk factors for recurrent acute otitis media in childhood. J Pediatr (Rio J) 2006; 82: 87-96.

8. Arroyave CM. Recurrent otitis media with effusion and food allergy in pediatric patients. Rev Alerg Mex 2001; 48: 141-4.

9. Lill C, Loader B, Seemann R, et al. Milk allergy is frequent in patients with chronic sinusitis and nasal polyposis. Am J Rhinol Allergy 2011; 25: e221-4.

10. Dellepiane RM, Pavessi P, Patria MF, et al. Atopy in preschool Italian children with recurrent respiratory infections. Pediatr Med Chir 2009; 31: 161-4.

11. Von Berg A, Filipiak-Pittroff B, Kreamer U, et al. GINIplus study group. Preventive effect of hydrolyzed infant formulas persists until age 6 years: long-term results from the German Infant Nutritional Intervention Study (GINI). J Allergy Clin Immunol 2008; 121: 1442-7.

12. Halken S, Hansen KS, Jacobsen HP, et al. Comparison of a partially hydrolyzed infant formula with two extensively hydrolyzed formulas for allergy prevention: a prospective randomized study. Pediatr Allergy Immunol 2000; 11: 149-61.

13. Oldaeus G, Anjou K, Bjorksten B, et al. Extensively and partially hydrolysed infant formulas for allergy prophylaxis. Arch Dis Child 1997; 77: 4-10.
14. Burks AW, Tang M, Sicherer S, et al. ICON: food allergy. J Allergy Clin Immunol 2012; 129: 906-20.

15. Venter C, Arshad SH. Guideline fever: an overview of DRACMA, US NIAID and UK NICE guidelines. Curr Opin ALlergy Clin Immunol 2012; 12: 302-15.

16. Spildennerd J, Belli D, Dupont C, et al. Hydrolysed $100 \%$ whey-based infant formula and prevention of atopic dermatitis: comparative pharmacoeconomic analyses. Ann Nutr Metab 2011; 59 (Suppl. 1): 44-52. 